\title{
Provincial experiments aim to lower public drug plan costs
}

$\mathrm{F}$ aced with tough economic times, Canadian governments are looking for ways to shrink their $\$ 11$ billion-plus share of the country's annual tab for prescription drugs.

In June, for example, western provinces and territories announced plans to establish a joint prescription drug buying plan to cash in on the buying power of 10 million people.

"We've been on different paths, but we've had discussions over the past months with other western jurisdictions about how to come together," says Kim Sharman, Manitoba's assistant deputy minister at the Ministry of Health and Healthy Living

The different paths taken by governments across Canada include striking deals directly with drug companies, negotiating with pharmacy associations, experimenting with tendering and competitive agreements, and working towards revising laws and regulations.

"There is lots of attention going to this and things are still in a state of transition," says Mark Ronayne, coauthor of 2 Competition Bureau Canada reports on the generic drug market.

Canada's drug prices are "straining personal budgets, business competitiveness, and a sustainable approach to financing our health care system," warned the Health Council of Canada in a report released earlier this year.

Up until 3 years ago, the amount that most provinces paid pharmacies for drugs purchased under public plans was based on Ontario's drug formulary.

Then, in 2006, Ontario slashed the amount it would pay for generic drugs to $50 \%$ of the brand name drug. At the same time, it banned rebates paid by generic manufacturers to pharmacies (although it allows manufacturers to pay "professional allowances" to pharmacies)

The province subsequently began negotiating directly with brand-name drug manufacturers (see sidebar on page E81).

Spending on brand-name drugs in

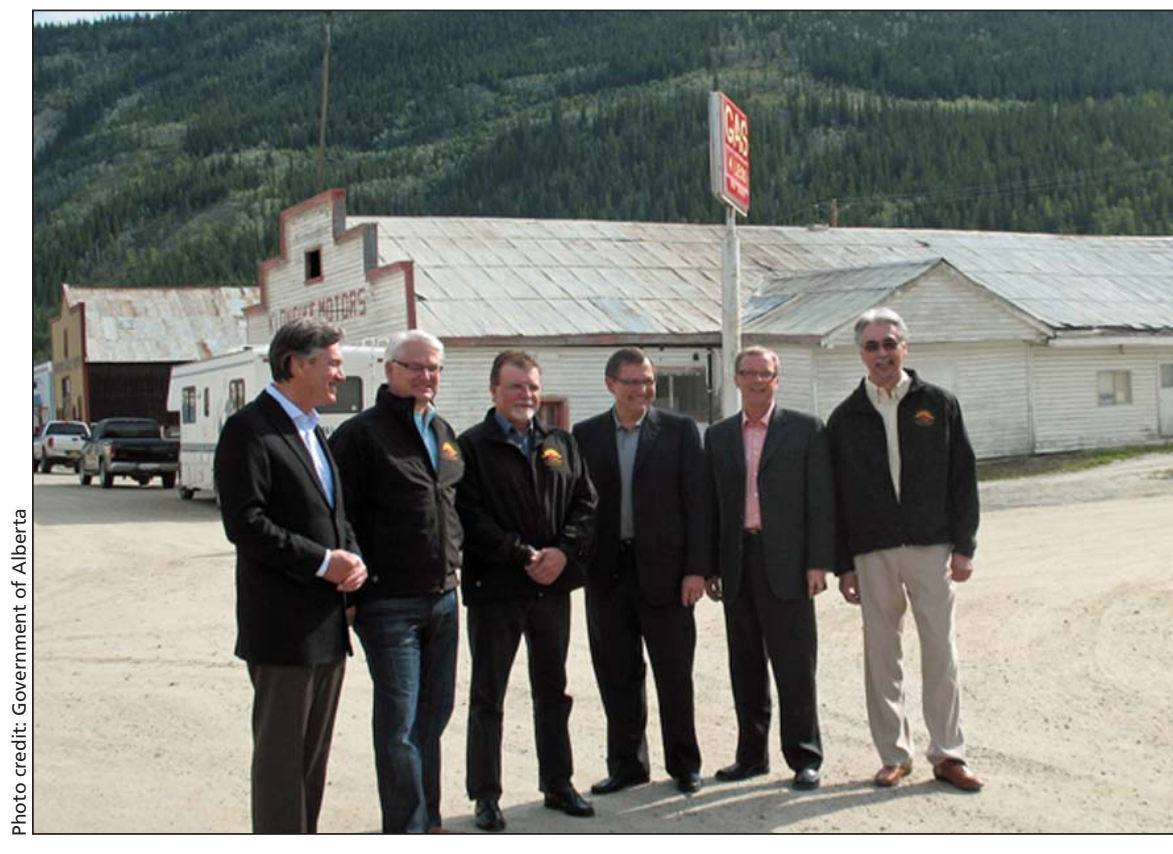

After their mid-June 2009 meeting in Dawson City, Yukon, premiers of Canada's western provinces and territories announced they will develop a joint western purchasing plan for pharmaceuticals.

Canada accounts for more than $75 \%$ of the approximately $\$ 25$ billion a year now spent on prescription drugs by both public and private payers.

Ontario and Quebec - Canada's 2 most populous provinces - reaped the benefit of the Ontario legislation in terms of lower drug costs. Prices for generic drugs dropped about $21 \%$ in both provinces after the new legislation, according to the Competition Bureau.

Quebec benefited alongside Ontario largely because of the "most favoured nation" clause in its legislation, which stipulates that the sale price to Quebec's drug plan cannot be higher than the price paid by other provincial drug plans.

Other provinces, however, did not obtain the same advantage; in fact, some are now paying more for generic drugs. When the Ontario pricing standard changed, "everything split apart and now there are different prices in different provinces for the same products," says Aidan Hollis, an economics professor at the University of Calgary.
As a result, most provinces have been reviewing and changing their approach to paying for drugs. They "want to come up with their own solution to the issue," says the Competition Bureau's Ronayne.

Quebec's clause "is the most awkward interprovincial problem," says Hollis, author of Generic Drug Pricing and Procurement: A Policy for Alberta.

Quebec's provision can act as a disincentive for manufacturers to offer lower prices to other provincial plans, notes the Competition Bureau's 2007 report, The Canadian Generic Drug Sector Study.

For example, since the 1970s, Saskatchewan has issued standing-offer contracts to entice prescription drug manufacturers to bid on supplying the entire province, which accounts for about $3 \%$ of the Canadian market, says Kevin Wilson, executive director of the drug plan for Saskatchewan Health.

But not many manufacturers "want to risk the Quebec market" by submit- 
ting prices they would also have to offer Quebec, says Wilson. As a result, the province has only 100 standingoffer contracts in place - half as many as it had 20 years ago, he says.

The Competition Bureau report concludes that abandoning the "most favoured nation" clause would be the most effective way to prevent its anticompetitive effects.

Steps have been taken by some provinces since 2006 to rein-in drug prices.

\section{British Columbia}

Under an interim agreement, supported by the provincial pharmacy association, the province's PharmaCare program reimburses pharmacists for new generic versions of brand-name drugs at $50 \%$ of the brand price. The agreement expires at the end of 2009, but the two parties have agreed to pursue a longer-term deal. In its bid to "moderate" generic drug costs, the province is interested "in how arrangements between pharmacies and suppliers are reflected in the cost that PharmaCare ultimately pays for drugs," states an email from the Ministry of Health Services.

\section{Manitoba}

In 2007, Manitoba established a drug management policy unit and, through a number of initiatives, saved $\$ 7.5$ million from March 2008 to February 2009. One aspect included negotiating agreements in which drug companies project sales volume and agree to a cost-sharing formula if spending on a drug exceeds the projection. The agreements can also require companies to provide funds to the province so it can conduct public education programs or further research about a drug, explains assistant deputy minister Sharman. To list generic drugs on the provincial formulary, Manitoba requires that it gets as good a price as other provincial buyers.

\section{Alberta}

In an effort to "align with pricing and purchasing models" in other provinces, Alberta is considering several policy options, such as reducing the price it will pay for generic drugs to $50 \%$ or less of the brand-name price, according to a recent presentation by Steve Long, executive director of pharmaceuticals for Alberta Health and Wellness. Currently, the province pays for generic drugs at $70 \%$ to $75 \%$ of the brand,

\section{Government prescription drug deals "anything but transparent"}

British Columbia and Ontario have experimented with a form of tendering for multi-source prescription drug purchases that involves confidential rebates paid by manufacturers to the provincial drug plans.

But the practice has proved controversial — BC faced a lawsuit after its attempt - and both provinces have put the competitive tendering practice on hold.

Ontario has also started to negotiate confidential discounts for brand-name drugs on its drug formulary.

"Governments are doing deals that are anything but transparent," says Jeff Poston, executive director of the Canadian Pharmacists Association.

Quebec legislation, which stipulates that it pay no more for prescription drugs than the lowest price paid by other provinces, "has led in part to some provinces getting into the secret rebates scheme," says Aidan Hollis, economics professor at the University of Calgary.

Governments benefit financially from confidential discounts, but the approach "can result in substantially higher prices for consumers" not covered by public drug plans, adds Hollis.

British Columbia's experiment involved asking the 2 manufacturers of the schizophrenia drug olanzapine to bid for the right to be the sole supplier to the province. The firms were required to provide both a list price and a postrebate price, Hollis stated in a 2008 policy brief for the Institute of Advanced Policy Research at his university.

The brand-name supplier, Eli Lilly, won the tender and the generic manufacturer, Novopharm, subsequently sued the province on the grounds that the process is "discriminatory". The case has not yet been settled, says Jeff Connell, spokesperson for the Canadian Generic Pharmaceutical Association.
The BC experiment was suspended for one year.

In Ontario, the public drug plan initiated competitive tendering in July 2008 for 4 drugs that account for annual sales of more than $\$ 80$ million, states the 2008 Competition Bureau report Benefiting from Generic Drug Competition in Canada: The Way Forward. Agreements would be awarded "based principally on the level of confidential rebates off of the Ontario formulary price of the relevant product," the report noted.

The competition for one drug, ranitidine, was dropped when the brand name manufacturer reduced its price for the Ontario drug formulary by $75 \%$, the report states. Helen Stevenson, the executive officer of the Ontario Public Drug Plan, says the competitive tendering process is now on hold pending an evaluation. Generic companies have told the province that they can't compete and offer lower prices because they are still making such large professional allowance payments to pharmacists, Stevenson says. (CMAJ 2009; etc. )

Stevenson defends the practice of confidential discounts off brand-name drugs as something that "happens in almost every jurisdiction I am aware of ... we are not an outlier by any means."

Pharmaceutical manufacturers told Ontario it would get a better discount "if actual prices and discounts were confidential" because the companies don't want to be forced to offer the lower prices in the much larger U.S. market, she says.

Before it introduced the Transparent Drug System for Patients Act in 2006, Ontario negotiated discounts off the maximum brand-name drug prices, established by the Patented Medicines Prices Review Board, but those discounted prices were published in the provincial formulary. 
Long stated in an email. The province plans to introduce legislative changes; guiding principles will include consistent and transparent pricing strategies and the proviso that all payers in the province benefit from changed pricing arrangements.

Meanwhile, Ontario plans to convene a meeting this summer with stakeholders — including pharmacy groups, drug manufacturers and private drug plan payers - to better understand the impact of the province's 2006 Transparent Drug System for Patients Act.

"We're also going to engage our provincial colleagues, partly so that they can benefit from hearing the facts that we found, the direction we are considering" and how this affects their programs, says Helen Stevenson, the executive officer of the Ontario Public Drug Program. The potential for inter provincial cooperation is "huge," she says.

A National Pharmaceutical Strategy was part of the 2004 Health Accord among Canadian governments and one of the "action items" identified by Canada's First Ministers was to "pursue purchasing strategies to obtain best prices for Canadians for drugs and vac- cines." However, the First Ministers stated in 2008 that a nation-wide approach to savings in pricing and purchasing is not realistic "at this time" and instead suggested interprovincial collaborations. - Ann Silversides, CMAJ

DOI:10.1503/cmaj.091257

Editor's note: A related article on generic drug pricing in Canada was published at www.cmaj.ca on Aug. 4. 